\title{
Sistema SENNOVA: Investigación, Innovación y Desarrollo Tecnológico al servicio de Colombia
}

\section{SENNOVA System: Research, Innovation and Technological Development at the service of Colombia}

\author{
Yuliana Andrea Areiza Rico \\ Líder Sennova, Centro de Servicios y Gestión Empresarial, SENA, Grupo - GIGAT, Medellín, Colombia. \\ yareiza@sena.edu.co \\ Editorial
}

La innovación tecnológica influye en todas las áreas de la vida; desde la cotidianidad de las personas hasta el trabajo de las empresas y el gobierno, y se evidencia incluso en las interacciones a escala mundial, ayudando a satisfacer las necesidades humanas básicas y proporcionando herramientas para mejorar la vida de las personas y explorar nuevas fronteras. La educación tecnológica permitirá a los estudiantes enfrentar los desafíos y oportunidades del siglo XXI.

La educación tecnológica se centra en desarrollar la capacidad de los estudiantes para trabajar de manera creativa y competente con tecnologías que son fundamentales para sus vidas. A medida que los estudiantes avanzan en su educación primaria y secundaria, alcanzan un nivel de alfabetización tecnológica que mejora su capacidad de éxito. El desarrollo de un país crece a medida que las habilidades y capacidades de sus habitantes crecen y se articulan a las dinámicas de evolución del entorno laboral, social, académico y cultural. Hoy en día las sociedades entienden la necesidad de trabajar en equipo, promover espacios colaborativos y desarrollar modelos de innovación que favorezcan la sostenibilidad y el desarrollo económico. En Colombia, el gobierno en todos sus niveles ha entendido esta dinámica, por lo que promueve la creación de ecosistemas de innovación, a través de mecanismos como convocatorias de financiación y jornadas de acompañamiento integral a ideas con potencial de materialización en la forma de un producto o servicio; en este escenario, y ante los desafíos que conlleva, surge como un aliado importante el Servicio Nacional de Aprendizaje SENA.

Más allá de los programas de formación, de iniciativas como Fondo Emprender, y los cursos a la medida de las necesidades de los usuarios, el SENA está apostando por soportar el trabajo colaborativo y articulado con los diferentes actores del ecosistema de ciencia, tecnología e innovación (CTel), como escenario de competitividad y productividad local, regional y nacional, a partir del cierre de brechas de talento humano, dotación de infraestructura y gestión de recursos desde los centros a través de su Sistema de Investigación, Innovación y Desarrollo Tecnológico SENNOVA [1].

Actividades tales como la co-ejecución de proyectos de I+D+i, asesorías, transferencias de conocimiento, asistencia técnica, servicios tecnológicos (laboratorios, pruebas y equipos), acompañamiento a desarrollo de productos y prototipos funcionales, extensionismo tecnológico, eventos de divulgación, pasantías nacionales e internacionales para aprendices, concursos y cursos de formación a la medida, constituyen algunos de los servicios acompañados o financiados desde SENNOVA, y que se articulan a través de proyectos en los centros de formación, para luego materializarse en servicios, producción académica y generación de nuevo conocimiento [2]. Así, cada centro de formación del SENA se convierte en un actor importante con infraestructura propia, recursos y una red de más de 117 sedes, 121 grupos de investigación avalados institucionalmente ante COLCIENCIAS y 25 parques tecnológicos (15 Tecnoparques y 10 Tecnoacademias) al servicio de los colombianos a nivel nacional, y todos a los cuales se puede acceder de manera gratuita [3].

Citar como:

Y. Areiza. “Sistema SENNOVA: Investigación, Innovación y Desarrollo Tecnológico al servicio de Colombia" Revista CINTEX, Vol. 24(1), pp. 10. 2019. 
Son 7 años fomentando la investigación en el SENA, desde la creación de SENNOVA con el acuerdo 0016 de 2012 [1] y aunque existen centros de formación con quizá muchísima más trayectoria, el rol del sistema SENNOVA ha sido fundamental para que hoy en día se pueda asegurar que no sólo se formen habilidades técnicas sino que desarrollemos competencias científicas y argumentativas que promuevan, desde el SENA, la apropiación de la cultura de la innovación en toda la sociedad colombiana. Muestra de ello son los resultados de investigación que hacen parte de este volumen de la Revista Cintex, y que dan fe de los avances de un proceso que se ha ido consolidando, y que esperamos que mantenga el crecimiento y mejoramiento continuo al que se aspira desde los procesos innovadores del Servicio Nacional de Aprendizaje a través de SENNOVA.

\section{REFERENCIAS}

[1] SENA, Acuerdo 016 de 2012, Por el cual se regula el Programa de Investigación, Desarrollo Tecnológico e Innovación y se subrogan los Acuerdos números 007 de 2006 y 004 de 2008., vol. 16. 2012.

[2] J. J. Castro Maldonado, J. A. Patiño Murillo, y C. Gómez López, «Procesos de I+D+i en el Centro de Servicios y Gestión Empresarial del Servicio Nacional de Aprendizaje SENA 2015-2017», Rev. Espac., vol. 39, n. ${ }^{\circ} 20$, p. 21, 2018.

[3] SENA, Guía de la línea programática de investigación aplicada: Grupos y semilleros de investigación v2, vol. 003. 2018. 